\title{
Review:
}

\section{Tea and human health: biomedical functions of tea active components and current issues*}

\author{
Zong-mao CHEN ${ }^{\dagger}$, Zhi LIN \\ (Tea Research Institute, Chinese Academy of Agricultural Sciences, Hangzhou 310008, China) \\ †E-mail: zmchen2006@163.com \\ Received Dec. 15, 2014; Revision accepted Dec. 28, 2014; Crosschecked Jan. 16, 2015
}

\begin{abstract}
Originating in China, tea and tea planting have spread throughout the world since the middle of the Tang dynasty. Now people from 160 countries in the world are accustomed to tea drinking. A brief history of tea's medicinal role in China and its spread to the world are introduced. The effectiveness of tea active components and tea drinking on major human diseases, including cancer, metabolic syndrome, cardiovascular disease, and neurodegenerative diseases, is discussed. Also presented are some related issues, such as the bioavailability of tea active components, the new formulations of tea polyphenols, and the safety for consumers of dietary supplements containing tea polyphenols.
\end{abstract}

Key words: Tea, Cancer, Metabolic syndrome, Cardiovascular disease, Neurodegenerative disease, Bioavailability doi:10.1631/jzus.B1500001

CLC number: Q946.8

\section{Introduction}

After water, tea is the most frequently consumed beverage worldwide. It is well known that the tea plant originated from the southwest of China. As early as 4000-5000 years ago, the Chinese people had become aware that tea could promote health and prevent some human diseases. This was recorded in ancient books on medicine, like Shen Nong's Herbal Classic. The planted acreage of the tea plant was small before A.D. 581 but expanded rapidly during the period of A.D. 581-618. It was recorded that the tea plant had then become a major crop in the southern part of China with vast plantation acreage. During the about 300 years of the Tang dynasty (A.D. 618-907), the tea industry underwent rapid development, which may be closely related to the healthpromoting effects of tea. Works on tea were published in this period, such as Tea Classic, which was written

\footnotetext{
* Project supported by the Consulting Project of the Chinese Academy of Engineering (No. 2012-XY-17), China

(1) ORCID: Zong-mao CHEN, http://orcid.org/0000-0003-2242-0113; Zhi LIN, http://orcid.org/0000-0001-6738-6663

(C) Zhejiang University and Springer-Verlag Berlin Heidelberg 2015
}

by $\mathrm{Yu} \mathrm{LU}$ of the Tang dynasty and is the earliest book on tea in the world. Even though the description of tea as a health-promoting and disease-preventing agent was found far before the Tang dynasty, the publication of Tea Classic greatly elevated the status of tea, and the imperial government even started to levy tea taxes to help replenish the state treasury. It was recorded that tea taxes collected during the reign of Tang Taizong (A.D. 627-649) amounted to around 400 million fen (wen) (Mair and Hoh, 2009).

There is an oft-quoted phrase that "The tea industry in China was developed in the Tang dynasty and flourished in the Song dynasty". According to the historical record, the planting of tea was so widespread in the southern part of China during the Song dynasty (A.D. 960-1279) that its distribution reached about three fourths of the territory of China in the twelfth century, indicating the popularity of tea consumption during that period. Tea had become a necessity of life for all citizens, from high officials, the intelligentsia, and down to the common people. Many new varieties of tea appeared in the Ming and Qing dynasties. The monumental medical monograph, The Compendium of Materia Medica, was completed by 
the famous medical and pharmacological scientist Shi-zhen LI in 1578 in the Ming dynasty. In total, 1892 mineral, botanical, and animal-origin medicines were recorded in this monograph, where tea was described as "tea, bitter and cold in nature, capable of lowering excessive internal heat". From then on, the understanding that tea is beneficial to human health has been well recognized not only in China but also around the world.

The spread of tea from China to the world dates back to the Tang dynasty mainly via the following three routes: (1) to Japan and Korea toward the east; (2) to Mongolia, Middle East, and Iran toward the northwest through land route, and further westward to Russia and other Slav countries; and (3) from Macau first to Holland through the sea route, then to France, Portugal, UK, and other European countries, and further to other countries including India, Ceylon (Sri Lanka), and African countries (Mair and Hoh, 2009). These routes, in consequence, created the history of tea planting and the custom of tea drinking in many countries in the world. Today, tea is planted in 60 countries, and people from more than 160 countries have formed the habit of tea drinking. The acceptance of and affection for tea by people from different countries and different ethnic groups are by and largely related to its beneficial effects on health.

The development of tea from a traditional Chinese medicine to a modern medicine started in the 1980 s. In a general spirit of "returning to nature", there sprang up a wealth of research on the effective components of tea that might prevent or control many important diseases. Research came from more than 20 countries and regions including China, USA, UK, France, Germany, Japan, India, Israel, Italy, the Netherlands, South Korea, Australia, Canada, etc. According to the database of ISI Web of Knowledge (Thomson Reuters), more than 800 papers have been published in academic journals each year since 2012 around the world. Many substantial and encouraging findings have been verified during the past 30 years, which altogether provide a solid foundation for the development of the tea industry and the promotion of tea consumption throughout the world.

This paper is not intended to be a thorough literature survey on the effects of tea on various human diseases and their mechanisms. However, the overall effects of tea on some important chronic diseases will be discussed and reviewed. In addition, the reasons for the differences between the results from animal models and from human epidemiological investigations are analyzed.

\section{Effectiveness of tea in preventing some important diseases}

\subsection{Prevention of cancer}

To date, much attention has been paid to the anticancer function of tea and tea catechins with animal and cell experiments. From the large volume of published papers on animal models, the overall conclusion is that most of the studies have reported cancer preventive activity of tea catechins against carcinogenesis at different organ sites with strong evidence (Yang et al., 2009; Kanwar et al., 2012). However, a few other studies argue that the cancer preventive effect of tea on the treatment group was not significantly different from that on the control group (Yang et al., 2009). In contrast to the strong evidence for the cancer preventive activities of tea constituents in animals, epidemiological studies are not consistent in demonstrating a cancer preventive effect of tea consumption in humans (Boehm et al., 2009; Clement, 2009).

Tea and its major components, such as green tea, black tea, tea polyphenols, and (-)-epigallocatechin3-gallate (EGCG) administered through drinking water or diet, have been demonstrated to inhibit tumorigenesis in many animal models for different organ sites, including the lung, oral cavity, esophagus, stomach, small intestine, colon, skin, liver, pancreas, bladder, prostate, and mammary glands. Although it was believed that EGCG and other catechins are the major active components of tea in the inhibition of tumorigenesis, research suggests that caffeine also shows effective inhibitory activity in the lung and skin (Yang et al., 2011). In addition, the polysaccharides from the tea flower are reported to have significant antitumor activities (Xu et al., 2012).

At least 20 studies have indicated the inhibitory effect of tea components on lung tumorigenesis. Most of the experiments were conducted in tobacco carcinogen-treated mouse models with a few studies in rat and hamster models. Green tea polyphenols have been shown to inhibit the growth of human lung cancer cells in test tubes (Kanwar et al., 2012). When tea preparations were administered during the initiation, promotion, or progression stages of carcinogenesis in 
rats, the inhibitory activities of theaflavin and EGCG have also been demonstrated. It was reported that there was no explicit relationship between the habit of tea drinking and the incidence of lung cancer in some investigations (Bonner et al., 2005; Li et al., 2008). However, one earlier population-based study demonstrated that green tea drinking was associated with decreased lung cancer risk (Ohno et al., 1995). A review of the epidemiological evidence by Arts (2008) reveals that high habitual intake of green tea significantly reduced the risk of lung cancer in only 4 out of 20 observational studies.

The inhibitory effects of tea on tumorigenesis in the digestive tract, including the oral cavity, esophagus, stomach, small intestine, and colon, have been found in more than 30 studies (Ju et al., 2005; Shimizu et al., 2005; Yang et al., 2009; 2011). A cohort study on 18244 Chinese men followed up for up to 12 years maintains that tea catechins may prevent gastric and esophageal cancers (Sun et al., 2002). Another cohort study on 72943 individuals implies a decreased risk for the development of gastric cancer in women, not in men, who drink more than five cups of tea per day (Suzuki et al., 2004). However, there were also some negative results (Galanis et al., 1998; Inoue et al., 1998; Huang et al., 1999; Zhou et al., 2008). In particular, Zhou et al. (2008) contended that there was no clear evidence that green tea could prevent the incidence of gastric cancer in the metaanalysis of 14 epidemiological studies involving 6123 cases and 134006 controls. Another meta-analysis of 13 epidemiological studies by Myung et al. (2009) stated that green tea consumption provided no preventive effect against the risk of development of gastric cancer. However, a reduction of $18 \%$ in the risk of lung cancer with the consumption of at least two cups of green tea per day was shown in the metaanalysis of 22 epidemiological studies (Tang et al., 2009). Additionally, according to a meta-analysis of 25 epidemiological studies on tea consumption and colorectal cancer (Sun et al., 2006), no association was found between black tea and colorectal cancer, and the results on green tea were unclear. Subsequently, a prospective study on women in Shanghai, China, found a reduced risk of colorectal cancer in green tea drinkers (Yang et al., 2007). On the other hand, a cohort study in Singapore (Sun et al., 2007) found that, for men, green tea consumption had a statistically non-significant increased risk for the advanced stage of colon cancer.
With respect to the effectiveness of tea compounds on mammary cancer, the association between the intake of green tea and breast cancer risk was assessed in six case-control studies. Four were population-based studies conducted among Asians in USA and Europe (Wu et al., 2003; 2007; Seely et al., 2005; Ogunleye et al., 2010), one in Shanghai, China (Shrubsole et al., 2009), and one hospital-based study was in Zhejiang Province, China (Zhang et al., 2007). All these six studies showed significant breast cancer risk reduction among the population with regular green tea drinking. In two of these case-control studies (Zhang et al., 2007; Shrubsole et al., 2009), an inverse association was observed between the cancer risk and the amounts of green tea drinking and the numbers of years of drinking. The combined odds ratio (OR) of 5604 cases and 5487 controls is 0.70 (95\% confidence interval (CI) $0.61-0.79$ ) for women who drink green tea regularly compared to those who do not drink green tea (Wu and Butler, 2011). By contrast, one epidemiological study (Sun et al., 2006) indicated that black tea drinking appears to be unrelated to breast cancer risk. Wu and $\mathrm{Yu}$ (2006) have suggested that the preventive effect of green tea against breast cancer may be related to the decreased blood estrogen levels found in green tea drinkers, while increased levels of this hormone were found in black tea drinkers. Leong et al. (2008) used the C3(1)/SV40 mouse model to evaluate the chemopreventive effects of green tea on human breast cancer, which showed that the administration of $0.5 \%$ polyphenol in drinking water significantly suppressed the development of tumor growth by $40 \%$ compared to tap water-fed animals. The association between green tea intake and breast cancer risk has been investigated in five prospective cohort studies conducted in Japan (Nagano et al., 2001; Suzuki et al., 2004; Iwasaki et al., 2010), Singapore (Yuan et al., 2005; Inoue et al., 2008), and Shanghai, China (Dai et al., 2010). These prospective cohort studies with a total of 2067 breast cancer cases, show that there is no association between the breast cancer risk and green tea drinking. The combined OR is 1.06 (95\% CI 0.93-1.20) for women who drink green tea regularly compared with non-green tea drinkers.

In relation to prostate cancer, Gupta et al. (2001) and Adhami et al. (2004) reported that tea polyphenols could inhibit the development of prostate cancer in an animal experiment, whereas in USA, Henning et al. (2011) compared the chemopreventive effects of 
green tea and black tea on prostate cancer. These studies included in vitro cell culture and in vivo animal and clinical trials, lending strong support for the chemopreventive effects of green tea, but the results from epidemiological studies of green tea consumption are mixed. The evidence for the chemopreventive effect of black tea is much weaker than that of green tea. Bettuzzi et al. (2006) reported a highly significant $(P<0.01)$ prevention result in humans using a high dose of green tea catechins $(200 \mathrm{mg}$ catechins $\times 3$ per day). While the incidence of tumors in men in the treated group was $3 \%$, it was $30 \%$ in the control group, indicating that a chemoprevention efficacy of $90 \%$ was achieved. A larger cohort study involving 49920 Japanese men followed up for up to 14 years showed a marked reduction in the risk of advanced prostate cancer in those with habitual consumption of green tea (Kurahashi et al., 2008). Yuan et al. (2011) reported that tea drinking could reduce the incidence of prostate cancer in two case studies, but in another four cohort studies, no inhibitory effects were found.

In summary, studies have reported cancer preventing effects of tea with consistently positive results on animals, but with less consistent, and even conflicting, results on humans. As for the actual mechanism of any anti-cancer activity of tea, candidates include the antioxidant, induction of phase II enzymes, inhibition of cell proliferation, induction of apoptosis, inhibition of angiogenesis (Fassina et al., 2004; Oak et al., 2005; Rodriguez et al., 2006), direct binding to target molecules, including the inhibition of selected protein kinases, matrix metalloproteinases, and DNA methyltransferases (Lee et al., 2005; Yang et al., 2006; Pham-Huy et al., 2008). The optimal dose of tea components for cancer reduction has yet to be established, thus demanding further scrutiny.

\subsection{Prevention of metabolic syndrome (MetS) and cardiovascular disease (CVD)}

The definition of MetS was first put forward by the World Health Organization (WHO) in 1999. More recently, the US National Cholesterol Education Program (NCEP) suggested that at least three of the following conditions must be met for diagnosis of MetS: abdominal obesity, elevated triglyceride level, reduced high-density lipocholesterol (HDL)-cholesterol level, elevated blood pressure, or elevated fasting glucose level (Grundy et al., 2005). It is an early induced factor of type 2 diabetes and a key risk factor for CVD.
In recent years, the beneficial effects of tea consumption on weight reduction and MetS have attracted huge public attention. An increasing amount of evidence suggests that several pathways in the development of MetS can be positively intervened upon by green tea catechins, especially EGCG.

Obesity is now recognized as a rapidly increasing worldwide threat to health, and many studies have been conducted to examine the influence of tea drinking on weight loss and MetS in animals. Of the 12 papers on tea consumption and body weight (BW) reduction in humans, 10 confirmed that drinking green tea or EGCG could reduce BW and fat or adipose weight (Sae-tan et al., 2011). Most of the studies also showed that supplementation with green tea catechins led to significant decreases in BW and body fat. The reduction in BW ranged from $0.7 \mathrm{~kg}$ (Auvichayapat et al., 2008) to $3.5 \mathrm{~kg}$ (Chantre and Lairon, 2002), and the loss in body fat ranged from $0.7 \mathrm{~kg}$ (Nagao et al., 2005) to $1.8 \mathrm{~kg}$ (Nagao et al., 2007). The dosage of EGCG used in the aforementioned investigations ranged from $100 \mathrm{mg} / \mathrm{d}$ (Nagao et al., 2007) to $540 \mathrm{mg} / \mathrm{d}$ (Chan et al., 2006). In the 26 human experiments conducted by Hursel et al. (2011) and Phung et al. (2010), most of the investigations discovered that tea drinking could reduce BW.

Wang et al. (2010) investigated the influence of tea drinking on the waist circumference, and the results were that for overweight Chinese taking green tea polyphenol (caffeine $<200 \mathrm{mg}$ ) $458-886 \mathrm{mg} / \mathrm{d}$ for $90 \mathrm{~d}$, the body fat could be decreased. A trial involving 132 overweight or obese women over 12 weeks demonstrated a significant reduction in abdominal fat and subcutaneous abdominal fat area in the group that consumed green tea compared with the control group (Maki et al., 2009). Hursel et al. (2011) indicated that both treatments of a mixture of catechins and caffeine and caffeine alone could increase energy expenditure. However, only a mixture of catechins and caffeine could increase the oxidation of body fat.

In general, most studies showed that supplementation with green tea catechins led to significant decrease in $\mathrm{BW}$ and body fat when compared with the baseline. A recent cross-over placebo controlled study (Venables et al., 2008) reported an increase of fat oxidation by $17 \%$ after a supplement containing various green tea polyphenols and $366 \mathrm{mg}$ EGCG (but not caffeine) compared with the control group. It is 
the first evidence that a single catechin, namely EGCG, has the potential to moderately affect fat oxidation. The optimal EGCG dose to increase fat oxidation and support a weight management has not yet been established. The dosage of EGCG used in those studies ranged from 100 (Nagao et al., 2007) to $540 \mathrm{mg} / \mathrm{d}$ (Chan et al., 2006), while the duration of the studies varied from $1 \mathrm{~d}$ (Komatsu, 2003; BérubéParent et al., 2005) to 13 weeks (Kovacs et al., 2004).

Some investigations on humans proved that tea drinking could alleviate MetS, reduce the incidence of type 2 diabetes, and reduce BW and low-density cholesterol (Basu et al., 2011). An epidemiological study conducted in Taiwan, China, showed that people with an average habitual tea consumption of $434 \mathrm{ml} / \mathrm{d}$ for more than ten years had a lower percentage of total body fat, smaller waist circumference, and decreased waist-to-hip ratio (Wu C.H. et al., 2003). Another investigation (Vernarelli and Lambert, 2013) conducted in USA suggested that hot tea drinking could decrease BW and MetS as well as the biomarker of CVD. Researchers from Taiwan (Chang et al., 2012) reasoned that if a patient drank more than $240 \mathrm{ml}$ tea every day, MetS could be improved.

The risk of developing diabetes increases with elevated grade of obesity. There have been intensive researches on the effects of natural ingredients on the prevention and treatment of diabetes. As a result of a survey on a population of 286701, Huxley et al. (2009) reported that the risk of type 2 diabetes could be lowered in those people who drank 3-4 cups of tea daily. An investigation on 17413 Japanese of 40 65 years of age indicated that the risk of type 2 diabetes was lowered by $33 \%$ among the people who drank more than 6 cups of tea daily (Iso et al., 2006). A study from the US reported that the risk of type 2 diabetes was reduced by $30 \%$ in people who consumed 4 cups of tea daily (Song et al., 2005). Eleven more studies concluded that catechins could reduce blood glucose or insulin level (Sae-tan et al., 2011). However, the optimal dose of EGCG for glucose control has not yet been established, though a dose range of EGCG $84-386 \mathrm{mg} / \mathrm{d}$ may be adequate to support glucose homeostasis according to existing findings (Hosoda et al., 2003; Tsuneki et al., 2004).

Preventing CVD through tea drinking is another research area of interest. Potenza et al. (2007) believed that tea drinking could lower blood pressure and improve endothelial functions. A Japanese study showed a potential elevation of blood triglyceride after oral administration of a corn oil emulsion $(8 \mathrm{ml} \mathrm{oil} / \mathrm{kg} \mathrm{BW})$ to male mice was significantly suppressed by using Pu-erh tea extract ( 50 and $100 \mathrm{mg} / \mathrm{kg}$ BW) and gallic acid (15 and $45 \mathrm{mg} / \mathrm{kg} \mathrm{BW}$ ) (Oi et al., 2012). An epidemiological survey conducted on 76979 people in Japan showed that the mortality induced by CVD was decreased when more than 6 cups of tea per day was consumed (Mineharu et al., 2011). Research in USA and Europe demonstrated that black tea drinking could decrease the risk of CVD (Deka and Vita, 2011). Another study (de Koning Gans et al., 2010) in the Netherlands involving 37514 healthy males and females who were followed up for 13 years indicated that the mortality from CVD was decreased by a daily consumption of 3-6 cups of black tea. It is suggested that the reduction in mortality can be attributed to the maintenance of cardiovascular health through green tea consumption (Nakachi et al., 2000; Sano et al., 2004; Yusuf et al., 2005). The majority of epidemiological studies confirmed that the cardiovascular system can benefit from tea consumption (Vita, 2003). However, an inverse correlation between green tea consumption and the mortality due to CVD was also found (Kuriyama et al., 2006). Epidemiological data suggested that black and green tea may reduce the risk of both coronary heart disease and stroke by $10 \%-20 \%$ (Bøhn et al., 2012). Oxidized low-density lipocholesterol (LDL) and hypertension are recognized as risk factors for CVD. Pearson et al. (1998) assessed the potential impact of green tea extract on LDL oxidation and concluded that LDL oxidation was inhibited by $3.9 \%$ after $12 \mathrm{~h}$ incubation with $0.08 \mathrm{mg} / \mathrm{kg}$ green tea extract. The inhibition was raised to $98 \%$ after incubation with $5 \mathrm{mg} / \mathrm{kg}$ green tea extracts. The effect of drinking green tea on developing hypertension was also evaluated in a cohort study with 1507 subjects (Yang et al., 2004). Compared with non-habitual tea drinkers, the risk of developing hypertension was cut down by $46 \%$ for those who consumed $120-599 \mathrm{ml} / \mathrm{d}$, and it was further reduced by $65 \%$ for those who consumed $600 \mathrm{ml} / \mathrm{d}$ or more. As yet the optimal daily dose for cardiovascular health has not been established. Based on the estimation that a single cup of tea brewed with $1.5 \mathrm{~g}$ of green tea contains 34.5-109.5 mg EGCG, a daily dosage of 
EGCG ranging from 69-657 mg (roughly equivalent to 2-6 cups of tea) appears to be beneficial to cardiovascular health (Thielecke and Boschmann, 2009).

\subsection{Prevention of neurodegenerative diseases}

The loss of cognitive function due to the structure and function damage of neuronal cells is a common process in neurodegenerative diseases including Alzheimer's disease (AD), Parkinson's disease (PD), and Huntington's disease (HD). AD is the most common of the neurodegenerative diseases with around 26 million patients worldwide. It is estimated that there will be 1 out of 85 persons with $\mathrm{AD}$ in the world by 2050 (Feng et al., 2013). AD is characterized by its influence on cognition and mental performance. Moreover, the abnormal accumulation of protein in the brain and the accumulation of amyloid- $\beta$ peptide $(A \beta)$ outside the cell result in oxidative damage, inflammation, disorder of synaptic function, the death of neuronal cells, and an increase in the calcium level in the cells (Barranco et al., 2009) At present, the prevention and control of neurodegenerative diseases is extremely difficult, partly because there are so many potential factors involved. The main area affected is in the brain. Thus, the medicine must have the ability to penetrate the blood-brain barrier, have potent anti-oxidative activity and chelating ability with ions in the brain during the pharmacological control process. Research started in the last century in pursuit of examining tea's possible influence on the memory and cognitive function of animals and humans. Dufresne and Farnworth (2001) from Newcastle University, UK, reported the influence of tea drinking on several enzymes related to memory function, which include acetyl cholinesterase, butyl cholinesterase, and $\beta$-secretase, etc. It was claimed that tea extracts could inhibit the activities of acetyl cholinesterase and butyl cholinesterase, and improve memory and cognitive function as well as brain function. EGCG has a role in regulating the genes related to the survival and death of brain cells in the sense that it can deactivate the expression of genes that promote the death and proapoptosis of cells and induce the protein kinase $\mathrm{C}$ in the neuronal cell, theanine, a unique amino acid first discovered in green tea, which also possesses a nerve protecting attribute (Kakuda, 2011). Substantial evidence indicates that an excess of $\mathrm{A} \beta$, which aggregates into toxic fibrillar deposits within the extracellular space of the brain, plays a central role in the pathogenesis of $\mathrm{AD}$. Considering the deleterious role of $\beta$-amyloid in the aetiology of neurodegradative diseases, the neuroprotective effects and antipathy to $A \beta$-induced toxicity of different tea extracts (green tea and black tea) and different tea components (epicatechin (EC), epigallocatechin (EGC), epicatechin gallate (ECG), EGCG, and gallic acid) were investigated using a primary culture of rat hippocampal cells (Bastianetto et al., 2005). Results implied that both green tea and black tea extracts displayed neuroprotective activity against $A \beta$ toxicity. The non-gallic forms of catechins (EC and EGC) failed to provide any protective effect against $A \beta$-induced toxicity. The flavan-3-ol gallate esters (ECG and EGCG) and gallic acid showed neuroprotective effect at 1-20,1-10, and 1-20 $\mu \mathrm{mol} / \mathrm{L}$, respectively (Bastianetto et al., 2005). In addition, many animal studies showed that tea flavan-3-ols are able to cross the blood-brain barrier (Lee et al., 2003; Bastianetto et al., 2005). Previous experiments hold that $\gamma$-aminobutyric acid (GABA) and L-theanine are also able to across the blood-brain barrier (Unno et al., 1999; Jäger and Saaby, 2011; da Silva Pinto, 2013).

According to the meta-analysis of 11 case studies and 1 cohort study, most researchers reported that tea drinking was found to be able to reduce the risk of AD and PD by $30 \%-60 \%$ (Checkoway et al., 2002; Tan et al., 2003; Li et al., 2012). A survey involving 1003 people over 70 years old in Japan discovered that the risk of decreased cognition in old Japanese who consumed two cups (100 ml/cup) or more of green tea every day was $64 \%$ lower than that in the population who consumed 3 cups or less per week. The same risk for the population who drank 4-6 cups of green tea per week (or 1 cup green tea daily) was $38 \%$ lower than that in the population who did not drink tea (Kuriyama et al., 2006). A survey conducted in USA indicated that the risk of PD in the population who drank 2 cups or more of tea per day was decreased (Hu et al., 2007).

Further, the influence of tea on cognition was examined among a group of 2031 people of 7074 years of age from Norway (Nurk et al., 2009). The score of cognitive ability in the group drinking black tea was significantly higher than that of the non-tea drinking group. Another study from Singapore on the relationship between tea drinking and PD among 200 
people showed that the risk of PD in the group of people who drank three cups of tea daily in a period of 10 years was decreased by $28 \%$ (Tan et al., 2003). Arab et al. (2011) studied the relationship between tea drinking and the occurrence of $\mathrm{AD}$ on 4809 people ( $\geq 65$ years old), and showed that the occurrences of AD were $0.20,0.38,0.43$, and 0.31 score decreased in the groups of people drinking tea $5-10$ times/month, 1-3 times/month, 1-4 times/week, and $>5$ times/week, respectively. They also found that tea drinking had a protective effect on cognitive decline in old females, but not in old males.

\section{Issues related to the research of tea drinking and human health}

As mentioned above, it has been shown in animal studies that tea components provide effective prevention for cancers in various organ sites, MetS, CVDs, neurodegradative diseases among others. However, epidemiological investigations in humans present some different patterns and inconsistent results between treated groups and control groups. In recent years, tea extracts have been increasingly used as anti-obesity agents. Despite the beneficial effects of tea being generally recognized, some side-effects were also reported with a high-dose of tea extracts, which therefore needs further examination.
3.1 Possible reasons for different results between animal experiments and epidemiological investigation in humans

As can be seen from Tables 1 and 2, tea polyphenols show good results in cancer prevention in experimental animals, whereas the results of epidemiological surveys on humans are not satisfactory. What is the reason for such differences? Possible reasons are discussed as follows.

Table 1 Inhibitory effect of tea and tea constituents on cancers in animal models

\begin{tabular}{lcc}
\hline \multirow{1}{*}{ Portion } & $\begin{array}{c}\text { Number of investigations showing } \\
\text { inhibitory effect }\end{array}$ \\
\cline { 2 - 3 } Lung & Yes & No \\
Oral cavity & 6 & 2 \\
Esophagus & 4 & 0 \\
Stomach & 9 & 0 \\
Intestine & 8 & 0 \\
Colon & $11(3)$ & 1 \\
Skin & $27(1)$ & 6 \\
Prostate & $4(5)$ & 0 \\
Mammary gland & $10(8)$ & 0 \\
Liver & 7 & 0 \\
Bladder & $3(1)$ & 1 \\
Pancreas & $2(2)$ & 0 \\
Thyroid & 1 & 0 \\
\hline${ }^{*}$ From 1965-2008 animal model information of PubMed Med- \\
line. The numbers of heterograft researches are listed in paren- \\
theses. Adapted with permission from Macmillan Publishers \\
Ltd.: Nat. Rev. Cancer (Yang et al., 2009), copyright 2009
\end{tabular}

Table 2 Investigation on the effect of tea drinking on the risk of cancer in humans*

\begin{tabular}{|c|c|c|c|c|c|}
\hline \multirow{2}{*}{ Position } & \multirow{2}{*}{ Tea } & \multicolumn{2}{|c|}{ Cohort study } & \multicolumn{2}{|c|}{ Case study } \\
\hline & & Risk decreased & Risk not decreased & Risk decreased & Risk not decreased \\
\hline \multirow[t]{2}{*}{ Colon } & Green tea & 2 & 5 & 4 & 3 \\
\hline & Black tea & 2 & 8 & 4 & 12 \\
\hline \multirow[t]{2}{*}{ Lung } & Green tea & 0 & 3 & 2 & 3 \\
\hline & Black tea & 0 & 8 & 6 & 4 \\
\hline Stomach & Green tea & 2 & 6 & 8 & 8 \\
\hline Esophagous & Black tea & 0 & 1 & 2 & 1 \\
\hline \multirow[t]{2}{*}{ Mammary gland } & Green tea & 3 & 4 & 3 & 0 \\
\hline & Black tea & 1 & 8 & 1 & 9 \\
\hline \multirow[t]{2}{*}{ Prostate } & Green tea & 2 & 0 & 2 & 0 \\
\hline & Black tea & 1 & 2 & 1 & 3 \\
\hline Pancreas & Black tea & 0 & 4 & 1 & 3 \\
\hline \multirow[t]{2}{*}{ Kidney and bladder } & Green tea & 0 & 1 & 0 & 4 \\
\hline & Black tea & 1 & 4 & 2 & 5 \\
\hline \multirow[t]{2}{*}{ Others } & Green tea & 0 & 2 & 5 & 1 \\
\hline & Black tea & 2 & 3 & 1 & 3 \\
\hline
\end{tabular}

${ }^{*}$ From 1965-2008 animal model information from PubMed Medline. Adapted with permission from Macmillan Publishers Ltd.: Nat. Rev. Cancer (Yang et al., 2009), copyright 2009 
3.1.1 Difference in the physiological and biochemical metabolisms between animals and humans

When catechins are orally administered in experimental animals, various catechin compounds are metabolized and moved in different styles via different routes. As shown in Table 3, the concentrations of various catechin compounds in various organs are quite different from each other. EGCG is excreted mainly through the bile to feces, with little excreted through the urine. Therefore, the concentration of EGCG is higher in the intestine and less in the kidney and bladder, whereas the concentration of EC is higher in the bladder, prostate, and kidney (Yang et al., 2009). Fujiki et al. (2012) investigated the systemic distribution of EGCG by using ${ }^{3} \mathrm{H}-\mathrm{EGCG}$ incubated into the stomach of mice and found that $24 \mathrm{~h}$ after administration, the small intestine, colon and stomach incorporated the most ${ }^{3} \mathrm{H}$-EGCG. It clearly indicates that EGCG is moved mainly via the digestive system (Table 4). Both human and animal studies have also shown that the bioavailabilities of EC and catechin are much higher than that of EGCG (Kim et al., 2000; Lee et al., 2002).

3.1.2 Difference between the experimental dosage and the actual concentration

The experimental dosage of tea polyphenols used in animals is much higher than the actual concentration of tea polyphenols in the organ and the blood of humans after tea drinking. The concentration of tea polyphenols used in experiment generally ranges from 20 to $100 \mu \mathrm{mol} / \mathrm{L}$, whereas the concentration of tea polyphenols in human blood after drinking tea is usually around $0.5 \mu \mathrm{mol} / \mathrm{L}$ (Yang and Hong, 2013). The difference is a factor of around 10-100. According to the experiment by Ullmann et al. (2003), a single oral dose administration of EGCG ranged from 50 to $1600 \mathrm{mg}$, but only at oral doses of more than $1 \mathrm{~g}$ EGCG, showed the maximal plasma EGCG concentrations greater than $1 \mu \mathrm{mol} / \mathrm{L}$. Peak concentrations were reached between 1.3 and $2.2 \mathrm{~h}$ after administration. The concentration of tea polyphenols in the blood and organs of humans may be lower than the active concentration of compounds. Tea polyphenols are a complex that is composed of multi-compounds, such as EC, EGC, ECG, and EGCG. These compounds are transferred and moved to various organs via various routes from the oral cavity after tea drinking. For example, EC and EGC are
Table 3 Distribution of green tea catechins in rat organs

\begin{tabular}{lccc}
\hline \multicolumn{1}{c}{ Organ } & $\begin{array}{c}\text { EGCG } \\
\text { (ng/g tissue) }\end{array}$ & $\begin{array}{c}\text { EGC } \\
\text { (ng/g tissue) }\end{array}$ & $\begin{array}{c}\text { EC } \\
\text { (ng/g tissue) }\end{array}$ \\
\hline Intestine & $487.8 \pm 121.5$ & $303.2 \pm 7.0$ & $925.0 \pm 261.5$ \\
Esophagus & $279.9 \pm 0$ & $185.9 \pm 8.1$ & $192.8 \pm 11.4$ \\
Prostate & $57.7 \pm 20.9$ & $250.6 \pm 66.1$ & $234.5 \pm 59.2$ \\
Spleen & $40.7 \pm 30.5$ & $93.0 \pm 22.5$ & $75.5 \pm 11.1$ \\
Bladder & $201.4 \pm 154.0$ & $810.4 \pm 299.4$ & $794.7 \pm 308.0$ \\
Lung & $16.7 \pm 0$ & $187.3 \pm 66.9$ & $228.9 \pm 89.1$ \\
Kidney & $58.4 \pm 8.3$ & $508.3 \pm 70.8$ & $425.0 \pm 84.2$ \\
Liver & $20.8 \pm 2.4$ & $50.2 \pm 17.4$ & $43.5 \pm 14.5$ \\
Heart & $3.5 \pm 0.4$ & $30.1 \pm 6.6$ & $20.7 \pm 5.9$ \\
Thyroid & $7.2 \pm 4.3$ & $48.8 \pm 7.6$ & $36.9 \pm 8.9$ \\
\hline Adapted from Kim et al. $(2000)$ by permission of Taylor \& Francis \\
Ltd.
\end{tabular}

Table 4 Incorporation of ${ }^{3} \mathrm{H}$-EGCG into target organs of mice

\begin{tabular}{lcc}
\hline \multicolumn{1}{c}{ Organ } & $\begin{array}{c}\text { Percentage of total } \\
\text { administered radi- } \\
\text { oactivity after } 24 \mathrm{~h}\end{array}$ & $\begin{array}{c}\text { Reduction of } \\
\text { tumor incidence }\end{array}$ \\
\hline Stomach & 3.93 & $62.0 \rightarrow 31.0$ \\
Duodenum & 0.35 & $63.0 \rightarrow 20.0$ \\
Small intestine & 5.69 & ND \\
Colon & 4.52 & $77.3 \rightarrow 38.1$ \\
Liver & 0.89 & $67.0 \rightarrow 33.0^{\mathrm{a}}$ \\
Brain & 0.32 & $83.3 \rightarrow 52.2$ \\
Kidney & 0.28 & $\mathrm{ND}$ \\
Lung & 0.16 & $\mathrm{ND}$ \\
Pancreas & 0.07 & $56.3 \rightarrow 65.5$ \\
Skin & $1.9 \times 10^{4} / 100 \mathrm{mg}$ & $65.0 \rightarrow 28.0$ \\
\hline
\end{tabular}

ND: not determined; ${ }^{a}$ Green tea extract. Adapted from Fujiki $e t$ al. (2012), with kind permission from Springer Science+Business Media

moved from the digestive system to the intestine and excreted in feces, whereas EGCG and ECG are moved from the kidney and bladder, and excreted in urine (Kim et al., 2000; Lee et al., 2002). Even if a high concentration of tea polyphenols is administered to humans orally, various catechin compounds will be moved and metabolized via different routes. Thus, the concentration of various catechins in different target organs will be lower than expected due to the dispersion of polyphenols.

\subsubsection{Difference between genders}

In the studies mentioned earlier, the efficacy in females is generally higher than that in males. This is mainly related to the differences in habits between the female and male. Generally, the percentage of smokers and wine consumers in males is higher than that in females. It is believed that nicotine and alcohol are 
interfering factors for the positive activity of tea polyphenols (Gao et al., 1994).

3.1.4 Low bio-availability of active components of tea polyphenols

The bio-availability of a compound in an animal is dependent on many internal and external factors (Bohn, 2014). Bio-availability is an important factor in bringing into play the biological activity of tea polyphenols in human organs. According to the theory put forward by Lipinski et al. (2001), the bio-availability of a compound is rather low in a biological organism when the compound possesses the following characteristics: (1) five or more hydrogen bond donors ( $\mathrm{OH}$ and $\mathrm{NH}$ groups), (2) 10 or more hydrogen bond donors ( $\mathrm{N}$ and $\mathrm{O}$ ), and (3) a molecular weight larger than $500 \mathrm{Da}$. The low bio-availability of EGCG is possibly related to its large molecular weight (458 Da) and with $8 \mathrm{OH}$ groups. Chen et al. (1997) reported that the bioavailability of EGCG in the rat was only $0.1 \%$ of the administered amount, much lower than that of EGC (14\%) and EC (31\%). In some Japanese studies on rats, it was reported that the level of EGCG in the organ and blood was only $0.0003 \%-0.4500 \%$ of the administered amount (Nakagawa and Miyazawa, 1997). The bio-availability of EGCG in mice was reported at $26.5 \%$, much higher than that in rat $(0.1 \%)$ (Lambert et al., 2003). Yang et al. (1999) showed that for $7 \mathrm{mg} / \mathrm{ml}$ green tea infusion held in the mouth for a certain time, the concentrations of EGCG and EGC in the saliva were 153 and $327 \mu \mathrm{mol} / \mathrm{L}$, respectively. This concentration was 400-1000 times higher than that in the blood after tea drinking. The molecular weights of theaflavin, EGCG, EGC, and EC are 564-868, 458, 306, and $290 \mathrm{Da}$, respectively, and the bio-availability of these compounds is in the order of EGC $>\mathrm{EC}>\mathrm{EGCG}>$ theaflavin.

\subsubsection{Intervention of interfering factors}

The feeding of animals under experiment was conducted under controlled conditions. However, several conditions are difficult to control in epidemiological studies on humans. Interfering factors such as smoking and wine-drinking are examples of such difficulties. Specifically, in a study on the influence of tea drinking on esophageal cancer in Shanghai, it was found that the risk of esophageal cancer for the females who drank tea but did not smoke could be decreased by $50 \%$. However, tea drinking showed no protective effects on the males who drank tea and most of whom had the habit of smoking. In another experiment where none of the tested males and females had the habit of smoking, it was reported that the risk of esophageal cancer of males who drank tea could be decreased by $57 \%$, almost the same as with the females (Gao et al., 1994).

\subsection{Concerns on the safety of tea polyphenols}

Along with the findings on the preventive and curative effects of tea, unexpected toxicity of high concentration of green tea polyphenols has been reported since the close of the last century. As early as 2003 , an anti-obesity product containing $25 \%$ catechins (actually a hydro-alcoholic extract from green tea) was put on the French and Spanish markets, and 13 cases ( 9 in France and 4 in Spain) were reported of the product causing the symptoms of increasing the enzyme activity in liver. A total of 79 cases of induced liver disease were reported in PubMed from January 1966 to June 2007. All the patients were taking green tea extracts (Mazzanti et al., 2009; Schönthal, 2011). This has drawn significant attention in a number of countries and demands an objective and scientific evaluation on the toxicity of green tea catechins. In 2008, 218 reports on green tea extracts (including 34 reports related to liver injury) were analyzed by the US Pharmacopeia. It was concluded that the consumption of highly concentrated green tea extracts in an empty stomach was more likely to lead to adverse effects (Sarma et al., 2008). The US Dietary Supplement Information Expert Committee (DSIEC) further suggested that green tea is a very popular beverage and yet seldom shows liver toxicity, and listed it in a safety level of 2 (Sarma et al., 2008). Research findings from Japan and UK as well as a report from Switzerland concluded that catechin does not produce genotoxicity nor show liver toxicity (Isbrucker et al., 2006a; 2006b; 2006c; Ogura et al., 2008). A study on the oral administration in mice conducted in Taiwan reported that it was safe even at a very high dosage of $2500 \mathrm{mg} /(\mathrm{kg} \cdot \mathrm{d}$ ) (which corresponds to a human weighing $60 \mathrm{~kg}$ taking $150 \mathrm{~g}$ green tea extracts daily) (Hsu et al., 2011). Isbrucker et al. (2006b) in Switzerland conducted a safety investigation on EGCG, where the no-observed adverse effect level (NOAEL) of EGCG in experimental rat intake via the stomach for $10 \mathrm{~d}$ was $500 \mathrm{mg} /(\mathrm{kg} \cdot \mathrm{d})$; for a human weighing $60 \mathrm{~kg}$, an oral administration of $30 \mathrm{~g}$ EGCG 
daily was also safe. In a collaborative investigation by scientists from USA and Egypt, $500-2500 \mathrm{mg} / \mathrm{kg}$ green tea extracts were administered to the mice via the stomach. The results revealed that even at a high dosage of $2500 \mathrm{mg} /(\mathrm{kg} \cdot \mathrm{d})$, the liver of experimental mice showed no significant side effects (Saleh et al., 2013). Krishna et al. (2011) pointed out in a review paper on liver toxicity induced by lipid depressing and dietary supplements that usnic acid and guggul extracts existed in these supplements and that these additives were demonstrated to be toxic to the liver.

In contrast to the opinions that green tea and its extracts even in high dosages are non-toxic to the liver, Lambert et al. (2007; 2010) administered $1500 \mathrm{mg} / \mathrm{kg}$ EGCG orally to mice on one occasion and found that the activity of alanine aminotransferases increased by 138 times, the toxicity in liver was increased, and the survival rate was decreased by $85 \%$. This implies that high dosage of EGCG was toxic to liver, which may be related to the pro-oxidation activity of EGCG.

Numerous studies from many countries indicate that, even using the maximum amount of consumption (13 $\mathrm{g}$ of tea every day) and the maximum brewing rate of green tea catechins calculated with the highest extracting rate $(20 \%)$, the highest consumption amount was $2.6 \mathrm{~g}$ of tea catechins. This figure is 11.5-58.4 times lower than the safety dosage of maximum daily intake of $150 \mathrm{~g}$ of green tea extracts (Saleh et al., 2013) or $30 \mathrm{~g}$ of EGCG (Isbrucker et al., 2006b). Therefore, we can safely conclude that it is impossible to damage human liver under traditional tea drinking conditions. The dietary supplements targeting obesity and manufactured from the green tea extracts possibly contain rather high amounts of tea polyphenols. However, if we control the amounts of daily intake under the reported low limit of safety dosage (30 g tea polyphenols), the daily dosage of tea polyphenols intake will be smaller by a substantial factor. Moreover, it is recommended that green tea extracts not be taken on empty stomach for the safety of consumers.

\section{Research trends on tea and human health in recent years}

Research on tea drinking and human health has undergone the following process: in vitro investigation, clinical investigation, epidemiological investi- gation, research on the metabolism and transformation of tea's active components in the human body, and research on the improvement of the bioavailability of tea's active components. In recent decades, particular attention has been paid to the improvement of the bioavailability of tea components in the human body, which mainly includes the following aspects.

\subsection{Preparation of nano-particles of tea's active components}

To improve the bioavailability of tea's active components in the human body, the possibility of the utilization of nano-technology was put forward in 2005. Siddiqui et al. (2009) proposed the concept of nanochemoprevention and prepared an EGCGpolylacetic acid (PLA) and EGCG-polyethylene glycol (PEG) capsule. The target is try to bring about systemic transmission and to improve the bioavailability of active components in the human body, and further to increase the bioactivity and preventive effects of tea polyphenols against cancer. Investigation showed that the PLA/PEG preparation was unstable in an acidic environment and thus unsuitable for direct oral administration, which gave way to the preparation of capsules. The new preparation could decrease the cumulative amounts in various organs and increase the deposition in the target organs. Due to the difference of the normal organ and the tumor organ in the vessel system and the improved permeation and retention effect, more active compounds could be cumulated in the tumor tissue. Results indicated that the effect of the new preparation on prostate cancer cells was 10 times higher than that of the preparation with non-nano materials after $24 \mathrm{~h}$ of administration. The $\mathrm{IC}_{50}$ was 3.74 and $43.6 \mu \mathrm{mol} / \mathrm{L}$, and the effective concentration in inducing the apoptosis of prostate cancer cells was 2.74 and $40 \mu \mathrm{mol} / \mathrm{L}$, respectively. In inhibiting the apoptosis, $3 \mu \mathrm{g}$ nano-EGCG showed a $57 \%$ inhibiting effect, whereas $30 \mu \mathrm{g}$ ordinary EGCG showed a 35\% inhibiting effect (Siddiqui et al., 2010). The new EGCG preparations, including PLA-PEG, PLGA-DMAB, and gelatin, etc., were used in the curative research on prostate cancer and mammary gland cancer, and it was demonstrated that the new preparations could improve the bioavailability of EGCG in animals (Bettuzzi et al., 2006; Shutava et al., 2009; Siddiqui et al., 2009). 


\subsection{Structural modifications of catechins}

Research on improving the bioactivity in the human body through the structural modification of catechins has been conducted since 2001. Lambert et al. (2006) substituted the eight $\mathrm{OH}$ groups on $\mathrm{A}, \mathrm{B}, \mathrm{D}$ rings of EGCG by the OAc group and used it as a pro-drug. When this new compound entered cells and formed the new EGCG compound under the influence of esterase, the amounts of new EGCG were increased by $2.8-30$ times, and the bioavailability in the blood and organs was increased at the same time. Landis-Piwowar et al. (2007) found that the bioavailability of EGCG was increased significantly by orally administering the pro-EGCG in rats. Compared with the control group, the recovery of EGCG was increased two-fold. Osanai et al. (2007) used a paraamino group to substitute the three acetyl groups on the D-ring of the above pro-drug and named it as $p-\mathrm{NH}_{2}$ EGCG. Results imply that this substituted compound was an enzyme inhibitor of the cancer cell. Its inhibitory activity was similar to that of acetylEGCG.

\subsection{New treatment strategies using the combina- tion of catechins and anticancer drugs}

Suganuma et al. (1999; 2010) conducted cancer treatment using a combination of EGCG and anticancer drugs sulindac and tamoxifen to conclude that EGCG had a synergic action with the drugs. Afterwards, they continued to conduct several investigations on the synergic action of EGCG and other anticancer drugs such as COX-2 inhibitors and retinoids. Lu et al. (2008) investigated the synergistic action of EGCG and atorvastatin in inhibiting chemically induced lung carcinogenesis in mice. The inhibitory action was associated with the synergistic induction of apoptosis. Suganuma et al. (2011) further studied the mechanism of the synergic action and found that a combination of EGCG and sulindac specifically induced upregulated expression of GADD153 and $p 21$ genes in PC-9 lung cancer cells, and the synergistic enhancements of apoptosis and GADD153 gene expression in human non-small cell lung cancer cells by the combination of EGCG and celecoxib were mediated through the activation of the mitogen-activated protein kinases (MAPK) signaling pathway. Based on previous evidence, they presented a new concept: green tea catechins as synergists with anticancer drugs. Kumazoe et al. (2013) also reported the synergistic effect on cancer inhibition between EGCG and anti-cancer agents. EGCG activated 67-kDa lamina receptors in multiple myeloma cells, resulting in elevated cyclic guanosinc monophosphate (cGMP) levels, which initiated apoptosis through the activation of protein kinase $\mathrm{C}-\delta$ (PKC $\delta$ ) and acid sphingomyelinase in a novel death pathway.

\section{Compliance with ethics guidelines}

Zong-mao CHEN and Zhi LIN declare that they have no conflict of interest.

This article does not contain any studies with human or animal subjects performed by any of the authors.

\section{References}

Adhami, V.M., Siddiqui, J.A., Ahmad, N., et al., 2004. Oral consumption of 5 green tea polyphenols inhibits insulinlike growth factor-1-induced signaling in an autochthonous mouse model of prostate cancer. Cancer Res., 64(23):8715-8722. [doi:10.1158/0008-5472.CAN-04-2840]

Arab, L., Biggs, M.L., O'Meara, E.S., et al., 2011. Gender differences in tea, coffee and cognitive decline in the elderly: the cardiovascular health study. J. Alzheimer's Dis., 27(3):553-566. [doi:10.3233/JAD-2011-110431]

Arts, I.C., 2008. A review of the epidemiological evidence on tea, flavonoids, and lung cancer. J. Nutr., 138(8):1561S$1566 \mathrm{~S}$.

Auvichayapat, P., Prapochanung, M., Tunkamnerdthai, O., et al., 2008. Effectiveness of green tea on weight reduction in obese Thais: a randomized controlled trial. Physiol. Behav., 93(3):486-491. [doi:10.1016/j.physbeh.2007.10.009]

Barranco, Q.J.L., Allam, M.F., del Castillo, A.S., et al., 2009. Parkinson's disease and tea: a quantitative review. $J$. Am. Coll. Nutr., 28(1):1-6. [doi:10.1080/07315724.2009. 10719754]

Bastianetto, S., Han, Y.S., Rémi, Q., 2005. Green tea and resveratrol as protective agents against neurotoxins. In: Luo, Y., Packer, L. (Eds.), Oxidative Stress and AgeRelated Neurodegeneration. CRC Press, Boca Raton, FL, USA, p.225-234.

Basu, A., Sanchez, K., Leyva, N.M., et al., 2011. Green tea minimally affects biomarkers of inflammation in obese subjects with metabolic syndrome. Nutrition, 27(2): 206-213. [doi:10.1016/j.nut.2010.01.015]

Bérubé-Parent, S., Pelletier, C., Doré, J., et al., 2005. Effects of encapsulated green tea and Guarana extracts containing a mixture of epigallocatechin-3-gallate and caffeine on $24 \mathrm{~h}$ energy expenditure and fat oxidation in men. Br. J. Nutr., 94(3):432-436. [doi:10.1079/BJN20051502]

Bettuzzi, S., Brausi, M., Rizzi, F., et al., 2006. Chemoprevention of human prostate cancer by oral administration of green tea catechins in volunteers with high-grade prostate intraepithelial neoplasia: a preliminary report from a one-year proof-of-principle study. Cancer Res., 66(2): 1234-1240. [doi:10.1158/0008-5472.CAN-05-1145]

Boehm, K., Borrelli, F., Ernst, E., et al., 2009. Green tea for the prevention of cancer. Cochrane Database Syst. Rev., CD005004. [doi:10.1002/14651858.CD005004.pub2] 
Bøhn, S.K., Ward, N.C., Hodgson, J.M., et al., 2012. Effects of tea and coffee on cardiovascular disease risk. Food Funct., 3(6):575-591. [doi:10.1039/c2fo10288a]

Bohn, T., 2014. Dietary factors affecting polyphenol bioavailability. Nutr. Rev., 72(7):429-452. [doi:10.1111/nure. 12114]

Bonner, M.R., Rothman, N., Mumford, J.L., et al., 2005. Green tea consumption, genetic susceptibility, PAH-rich smoky coal, and the risk of lung cancer. Mutat. Res. Gen. Toxicol. Envir. Mutag., 582(1-2):53-60. [doi:10.1016/j. mrgentox.2004.12.008]

Chan, C.C., Kao, M.W., Ng, E.H., et al., 2006. Effects of Chinese green tea on weight, and hormonal and biochemical profiles in obese patients with polycystic ovary syndrome - a randomized placebo-controlled trial. J. Soc. Gynecol. Investig., 13(1):63-68. [doi:10.1016/j. jsgi. 2005.10.006]

Chang, C.S., Chang, Y.F., Liu, P.Y., et al., 2012. Smoking, habitual tea drinking and metabolic syndrome in elderly men living in rural community: the Tianliao old people (TOP) study 02. PLoS ONE, 7(6):e38874. [doi:10.1371/ journal.pone.0038874]

Chantre, P., Lairon, D., 2002. Recent findings of green tea extract AR25 (Exolise) and its activity for the treatment of obesity. Phytomedicine, 9(1):3-8. [doi:10.1078/09447113-00078]

Checkoway, H., Powers, K., Smith-Weller, T., et al., 2002. Parkinson's disease risks associated with cigarette smoking, alcohol consumption, and caffeine intake. Am. $J$ Epidemiol., 155(8):732-738. [doi:10.1093/aje/155.8.732]

Chen, L., Lee, M.J., Li, H., et al., 1997. Absorption, distribution, elimination of tea polyphenols in rats. Drug Metab. Dispos., 25(9):1045-1050.

Clement, Y., 2009. Can green tea do that? A literature review of the clinical evidence. Prev. Med., 49(2-3):83-87. [doi:10.1016/j.ypmed.2009.05.005]

Dai, Q., Shu, X.O., Li, H., et al., 2010. Is green tea drinking associated with a later onset of breast cancer? Ann. Epidemiol., 20(1):74-81. [doi:10.1016/j.annepidem.2009.09. 005]

da Silva Pinto, M., 2013. Tea: a new perspective on health benefits. Food Res. Int., 53(2):558. [doi:10.1016/j. foodres.2013.01.038]

Deka, A., Vita, J.A., 2011. Tea and cardiovascular disease. Pharmacol. Res., 64(2):136-145. [doi:10.1016/j.phrs. 2011.03.009]

de Koning Gans, J.M., Uiterwaal, C.S., van der Schouw, Y.T., et al., 2010. Tea and coffee consumption and cardiovascular morbidity and mortality. Aterioscler. Thromb. Vasc. Biol., 30(8):1665-1671. [doi:10.1161/ATVBAHA.109. 201939]

Dufresne, C.J., Farnworth, E.R., 2001. A review of latest research findings on the health promotion properties of tea. J. Nutr. Biochem., 12(7):404-421. [doi:10.1016/ S0955-2863(01)00155-3]

Fassina, G., Venè, R., Morini, M., et al., 2004. Mechanisms of inhibition of tumor angiogenesis and vascular tumor growth by epigallocatechin-3-gallate. Clin. Cancer Res., 10(14):4865-4873. [doi:10.1158/1078-0432.CCR-03-0672]

Feng, L., Ng, T.P., Kua, E.H., et al., 2013. Tea and the cognitive function of elderly people: evidence from neurobi- ology and epidemiology. In: Preedy, V.R. (Ed.), Tea in Health and Disease Prevention. AP Press, London, p.1325-1336.

Fujiki, H., Imai, K., Nakachi, K., et al., 2012. Challenging the effectiveness of green tea in primary and tertiary cancer prevention. J. Cancer Res. Clin. Oncol., 138(8):12591270. [doi:10.1007/s00432-012-1250-y]

Galanis, D.J., Kolonel, L.N., Lee, J., et al., 1998. Intakes of selected foods and beverages and the incidence of gastric cancer among the Japanese residents of Hawaii: a prospective study. Int. J. Epidemiol., 27(2):173-180. [doi:10. 1093/ije/27.2.173]

Gao, Y.T., McLaughlin, J.K., Blot, W.J., 1994. Reduced risk of esophageal cancer associated with green tea consumption. J. Natl. Cancer Inst., 86(11):855-858. [doi:10.1093/ jnci/86.11.855]

Grundy, S.M., Cleeman, J.I., Daniels, S.R., et al., 2005. Diagnosis and management of the metabolic syndrome: an American Heart Association/National Heart, Lung, and Blood Institute Scientific Statement. Circulation, 112(17): 2735-2752. [doi:10.1161/CIRCULATIONAHA.105.169404]

Gupta, S., Hastak, K., Ahmad, N., et al., 2001. Inhibition of prostate carcinogenesis in TRAMP mice by oral infusion of green tea polyphenols. PNAS, 98(18):10350-10355. [doi:10.1073/pnas.171326098]

Henning, S.M., Wang, P.W., Heber, D., 2011. Chemopreventive effects of tea in prostate cancer: green tea versus black tea. Mol. Nutr. Food Res., 55(6):905-920. [doi:10. 1002/mnfr.201000648]

Hosoda, K., Wang, M.F., Liao, M.L., et al., 2003. Antihypeglyceic effect of Oolong tea in type-2 diabetes. Diab. Care, 26(6):1714-1718. [doi:10.2337/diacare.26.6.1714]

Hsu, Y.W., Tsai, C.F., Chen, W.K., et al., 2011. A subacute toxicity evaluation of green tea (Camellia sinensis) extract in mice. Food Chem. Toxicol., 49(10):2624-2631. [doi:10.1016/j.fct.2011.07.007]

Hu, G., Bidel, S., Jousilshti, P., et al., 2007. Coffee and tea consumption and the risk of Parkinson's disease. Mov. Disord., 22(15):2242-2248. [doi:10.1002/mds.21706]

Huang, X., Tajima, K., Hamajima, N., et al., 1999. Effect of life styles on the risk of subsite-specific gastric cancer in those with and without family history. J. Epidemiol., 9(1):40-45. [doi:10.2188/jea.9.40]

Hursel, R., Viechtbauer, W., Dulloo, A.G., et al., 2011. The effects of catechin rich teas and caffeine on energy expenditure and fat oxidation: a meta-analysis. Obes. Rev., 12(7):573-581. [doi:10.1111/j.1467-789X.2011.00862.x]

Huxley, R., Lee, C.M., Barzi, F., et al., 2009. Coffee, decaffeinated coffee, and tea consumption in relation to incident type 2 diabetes mellitus: a systematic review with meta-analysis. Arch. Intern. Med., 169(22):2053-2063. [doi:10.1001/archinternmed.2009.439]

Inoue, M., Tajima, K., Hirose, K., et al., 1998. Tea and coffee consumption and the risk of digestive tract cancers: data from a comparative case-referent study in Japan. Cancer Causes Control, 9(2):209-216. [doi:10.1023/A:10088905 29261]

Inoue, M., Robien, K., Wang, R., et al., 2008. Green tea intake, MTHFR/TYMS genotype and breast cancer risk: the Singapore Chinese Health Study. Carcinogenensis, 29(10):1967-1972. [doi:10.1093/carcin/bgn177] 
Isbrucker, R.A., Bausch, J., Edwards, J.A., et al., 2006a. Safety studies on epigallocatechin-3-gallate (EGCG) preparations. Part 1: genotoxicity. Food Chem. Toxicol., 44(5): 626-635. [doi:10.1016/j.fct.2005.07.005]

Isbrucker, R.A., Edwards, J.A., Wolz, E., et al., 2006b. Safety studies on epigallocatechin-3-gallate (EGCG) preparations. Part 2: dermal, acute and short-term toxicity studies. Food Chem. Toxicol., 44(5):636-650. [doi:10.1016/j.fct. 2005.11.003]

Isbrucker, R.A., Bausch, J., Edwards, J.A., et al., 2006c. Safety studies on epigallocatechin-3-gallate (EGCG) preparations. Part 3: teratogenicity and reproductive toxicity studies in rats. Food Chem. Toxicol., 44(5):651-661. [doi:10.1016/j.fct.2005.11.002]

Iso, H., Date, C., Wakai, K., et al., 2006. The relationship between green tea and total caffeine intake and risk for self-reported type 2 diabetes among Japanese adults. Ann. Int. Med., 144(8):554-562. [doi:10.7326/0003-4819-1448-200604180-00005]

Iwasaki, M., Inoue, M., Sasazuki, S., et al., 2010. Green tea drinking and subsequent risk of breast cancer in a population to based cohort of Japanese women. Breast Cancer Res., 12(5):R88. [doi:10.1186/bcr2756]

Jäger, A.K., Saaby, L., 2011. Flavonoids and the CNS. Molecules, 16(2):1471-1485. [doi:10.3390/molecules16021471]

Ju, J., Hong, J., Zhou, J.N., et al., 2005. Inhibition of intestinal tumorigenesis in $A p c^{\mathrm{min} /+}$ mice by (-)-epigallocatechin3-gallate, the major catechin in green tea. Cancer Res., 65(22):10623-10631. [doi:10.1158/0008-5472.CAN-051949]

Kakuda, T., 2011. Neuroprotective effects of theanine and its preventive effects on cognitive dysfunction. Pharmacol. Res., 64(2):162-168. [doi:10.1016/j.phrs.2011.03.010]

Kanwar, J., Taskeen, M., Mohammad, I., et al., 2012. Recent advances on tea polyphenols. Front. Biosci., 4(1): 111-131. [doi:10.2741/E363]

Kim, S., Lee, M.J., Hong, J., et al., 2000. Plasma and tissue levels of tea catechins in rats and mice during chronic consumption of green tea polyphenols. Nutr. Cancer, 37(1):41-48. [doi:10.1207/S15327914NC3701_5]

Komatsu, T., 2003. Oolong tea increases energy metabolism in Japanese females. J. Med. Invest., 50(3-4):170-175.

Kovacs, E.M., Lejeune, M.P., Nijs, I., et al., 2004. Effects of green tea on weight maintenance after body-weight loss. Br. J. Nutr., 91(3):431-437. [doi:10.1079/BJN20041061]

Krishna, Y.R., Mittal, V., Grewal, P., et al., 2011. Acute liver failure caused by 'fat burners' and dietary supplements: a case report and literature review. Can. J. Gastroenterol., 25(3): $157-160$.

Kumazoe, M., Sugihara, K., Tsukamoto, S., et al., 2013. 67-kDa laminin receptor increases cGMP to induce cancerselective apoptosis. J. Clin. Invest., 123(2):787-799. [doi: 10.1172/JCI64768]

Kurahashi, N., Sasazuki, S., Iwasaki, M., et al., 2008. Green tea consumption and prostate cancer risk in Japanese men: a prospective study. Am. J. Epidemiol., 167(1):71-77. [doi:10.1093/aje/kwm249]

Kuriyama, S., Shimazu, T., Ohmori, K., et al., 2006. Green tea consumption and mortality due to cardiovascular disease, cancer and all causes in Japan: the Ohsaki study. JAMA, 296(10):1255-1265. [doi:10.1001/jama.296.10.1255]
Lambert, J.D., Lee, M.J., Lu, H., et al., 2003. Epigallocatechin3 -gallate is absorbed but extensively gucuronidated following oral administration to mice. J. Nutr., 133(12): 4172-4177.

Lambert, J.D., Sang, S., Hong, J., et al., 2006. Peracetylation as a means of enhancing in vitro bioactivity and bioavailability of epigallocatechin-3-gallate. Drug Metab. Dispos., 34(12):2111-2116. [doi:10.1124/dmd.106.011460]

Lambert, J.D., Sang, S., Lu, A.Y., et al., 2007. Metabolism of dietary polyphenols and possible interactions with drugs. Curr. Drug Metab., 8(5):499-507. [doi:10.2174/1389200 07780866870]

Lambert, J.D., Kennett, M.J., Sang, S., et al., 2010. Hepatotoxicity of high oral dose (-)-epigallocatechin-3-gallate in mice. Food Chem. Toxicol., 48(1):409-416. [doi:10. 1016/j.fct.2009.10.030]

Landis-Piwowar, K.R., Huo, C.D., Chen, D., et al., 2007. Methylation suppresses the proteasome-inhibitory function of green tea polyphenols. J. Cell. Physiol., 213(1): 252-260. [doi:10.1002/jcp.21124]

Lee, M.J., Maliakal, P., Chen, L., et al., 2002. Pharmacokinetics of tea catechins after ingestion of green tea and (-)-epigallocatechin-3-gallate by humans: formation of different metabolites and individual variability. Cancer Epidemiol. Biomarkers Prev., 11(10 Pt 1):1025-1032.

Lee, S.R., Im, K.J., Suh, S.I., et al., 2003. Protective effect of green tea polyphenol (-)-epigallocatechin gallate and other antioxidants on lipid peroxidation in gerbil brain homogenates. Phytother. Res., 17(3):206-209. [doi:10. 1002/ptr.1090]

Lee, W.J., Shim, J.Y., Zhu, B.T., 2005. Mechanisms for the inhibition of DNA methyltransferases by tea catechins and bioflavonoids. Mol. Pharmacol., 68(4):1018-1030. [doi:10.1124/mol.104.008367]

Leong, H., Mathur, P.S., Geene, G.L., 2008. Inhibition of mammary tumorigenesis in the C3(1)/SV40 mouse model by green tea. Breast Cancer Res. Treat., 107(3):359-369. [doi:10.1007/s10549-007-9568-x]

Li, F.J., Ji, H.F., Shen, L., 2012. A meta-analysis of tea drinking and risk of Parkinson's disease. Sci. World J., 923464. [doi:10.1100/2012/923464]

Li, Q., Kakizuki, M., Kuriyama, S., et al., 2008. Green tea consumption and lung cancer risk: the Ohsaki study. Br. J. Cancer, 99(7):1179-1184. [doi:10.1038/sj.bjc.6604645]

Lipinski, C.A., Lombardo, F., Dominy, B.W., et al., 2001. Experimental and computational approaches to estimate solubility and permeability in drug discovery and developmental settings. Adv. Drug Deliv. Rev., 46(1-3):3-25. [doi:10.1016/S0169-409X(96)00423-1]

Lu, G., Xiao, H., You, H., et al., 2008. Synergistic inhibition of lung tumorigenesis by a combination of green tea polyphenols and atrovastatin. Clin. Cancer Res., 14(15): 4981-4988. [doi:10.1158/1078-0432.CCR-07-1860]

Mair, V.H., Hoh, E., 2009. The True History of Tea. Thames Hudson, London.

Maki, K.C., Reeves, M.S., Farmer, M., et al., 2009. Green tea catechin consumption enhances exercise-induced abdominal fat loss in overweight and obese adults. J. Nutr., 139(2):264-270. [doi:10.3945/jn. 108.098293]

Mazzanti, G., Menniti-Ippolito, F., Moro, P.A., et al., 2009. Hepatotoxicity from green tea: a review of the literature 
and two unpublished cases. Eur. J. Clin. Pharmacol., 65(4):331-341. [doi:10.1007/s00228-008-0610-7]

Mineharu, Y., Koizumi, A., Wada, Y., et al., 2011. Coffee, green tea, black tea and Oolong tea consumption and risk of mortality from cardiovascular disease in Japanese men and women. J. Epidemiol. Community Health, 65(3): 230-240. [doi:10.1136/jech.2009.097311]

Myung, S.K., Bae, W.K., Oh, S.M., et al., 2009. Green tea consumption and risk of stomach cancer: a meta-analysis of epidemiologic studies. Int. J. Cancer, 124(3):670-677. [doi:10.1002/ijc.23880]

Nagano, J., Kono, S., Preston, D.L., et al., 2001. A prospective study of green tea consumption and cancer incidence, Hiroshima and Nagasaki (Japan). Cancer Causes Control, 12(6):501-508. [doi:10.1023/A:1011297326696]

Nagao, T., Komine, Y., Soga, S., et al., 2005. Ingestion of a tea rich in catechins leads to a reduction in body fat and malondialdehyde-modified LDL in men. Am. J. Clin. Nutr., 81(1):122-129.

Nagao, T., Hase, T., Tokimitsu, I., 2007. A green tea extract high in catechins reduces body fat and cardiovascular risk in humans. Obesity, 15(6):1473-1483. [doi:10.1038/oby. 2007.176]

Nakachi, K., Matsuyama, S., Miyake, S., et al., 2000. Preventive effects of drinking green tea on cancer and cardiovascular disease: epidemiological evidence for multiple targeting prevention. Biofactors, 13(1-4):49-54. [doi:10. 1002/biof.5520130109]

Nakagawa, K., Miyazawa, T., 1997. Absorption and distribution of tea catechin, (-)-epigallocatechin-3-gallate, in the rat. J. Nutr. Sci. Vitaminol., 43(6):679-684. [doi:10. 3177/jnsv.43.679]

Nurk, E., Refsum, H., Drevon, C.A., et al., 2009. Intake of flavonoid-rich wine, tea, and chocolate by elderly men and women is associated with better cognitive test performance. J. Nutr., 139(1):120-127. [doi:10.3945/jn.108. 095182]

Oak, M.H., Bedoui, J.E., Schini-Kerth, V.B., 2005. Antiagiogenic properties of natural polyphenols from red wine and green tea. J. Nutr. Biochem., 16(1):1-8. [doi:10.1016/j. jnutbio.2004.09.004]

Ogunleye, A.A., Xue, F., Michels, K.B., 2010. Green tea consumption and breast cancer risk of recurrence: a metaanalysis. Breast Cancer Res. Treat., 119(2):477-484. [doi:10.1007/s10549-009-0415-0]

Ogura, R., Ikeda, N., Yuki, K., et al., 2008. Genotoxicity studies on green tea catechin. Food Chem. Toxicol., 46(6):2190-2200. [doi:10.1016/j.fct.2008.02.016]

Ohno, Y., Wakai, K., Genka, K., 1995. Tea consumption and lung cancer risk: a case-control study in Okinawa, Japan. Jpn. J. Cancer Res., 86(11):1027-1034. [doi:10.1111/j. 1349-7006.1995.tb03016.x]

Oi, Y., Hou, I.C., Fujita, H., et al., 2012. Antiobesity effects of Chinese black tea (Pu-erh tea) extract and gallic acid. Phytother. Res., 26(4):475-481. [doi:10.1002/ptr.3602]

Osanai, K., Landis-Piwowar, K.R., Dou, Q.P., et al., 2007. A para-amino substituent on the D-ring of green tea polyphenol epigallocatechin-3-gallate as a novel proteasome inhibitor and cancer celosis inducer. Bioorg. Med. Chem., 15:492-496. [doi:10.1016/j.bmc.2007.05.04]

Pearson, D.A., Frakel, E.N., Aeschbach, R., et al., 1998. Inhi- bition of endothelial cell mediated low-density lipoprotein oxidation by green tea extracts. J. Agric. Food Chem., 46(4):1445-1449. [doi:10.1021/jf970889b]

Pham-Huy, L.A.N., He, H., Pham-Huy, C., 2008. Green tea and health: an overview. J. Food Agric. Environ., 6(1):6-13.

Phung, O.J., Baker, W.L., Matthews, L.J., et al., 2010. Effect of green tea catechins with or without caffeine on anthropometric measures: a systematic review and metaanalysis. Am. J. Clin. Nutr., 91(1):73-81. [doi:10.3945/ ajcn.2009.28157]

Potenza, M.A., Marasciulo, F.L., Tarquinio, M., et al., 2007. EGCG, a green tea polyphenol, improves endothelial function and insulin sensitivity, reduces blood pressure, and protects against myocardial I/R injury in SHR. Am. J. Physiol. Endocrinol. Metab., 292(5):E1378-E1387. [doi:10.1152/ajpendo.00698.2006]

Rodriguez, S.K., Guo, W., Liu, L., et al., 2006. Green tea catechin, epigallocatechin-3-gallate, inhibits vascular endothelial growth factor angiogenic signaling by disrupting the formation of a receptor complex. Int. J. Cancer, 118(7):1635-1644. [doi:10.1002/ijc.21545]

Sae-tan, S., Grove, K.A., Lambert, J.D., 2011. Weight control and prevention of metabolic syndrome by green tea. Phamacol. Res., 64(2):146-154. [doi:10.1016/j.phrs.2010. 12.013]

Saleh, I.G., Ali, Z., Abe, N., et al., 2013. Effect of green tea and its polyphenols on mouse liver. Fitoterapia, 90: 151-159. [doi:10.1016/j.fitote.2013.07.014]

Sano, J., Inami, S., Seimiya, K., et al., 2004. Effects of green tea intake on the development of coronary artery disease. Circul. J., 68(7):665-670. [doi:10.1253/circj.68.665]

Sarma, D.N., Barrett, M.L., Chavez, M.L., et al., 2008. Safety of green tea extracts: a systematic review by the US Pharmacopeia. Drug Safety, 31(6):469-484. [doi:10.2165/ 00002018-200831060-00003]

Schönthal, A.H., 2011. Adverse effects of concentrated green tea extracts. Mol. Nutr. Food Res., 55(6):874-885. [doi:10.1002/mnfr.201000644]

Seely, D., Mills, E.J., Wu, P., et al., 2005. The effects of green tea consumption on incidence of breast cancer and recurrence of breast cancer: a systemic review and metaanalysis. Integr. Cancer Ther., 4(2):144-155. [doi:10. 1177/1534735405276420]

Shimizu, M., Deguchi, A., Hara, Y., et al., 2005. EGCG inhibits activation of the insulin-like growth factor-1 receptor in human colon cancer cells. Biochem. Biophys. Res. Commun., 334(3):947-953. [doi:10.1016/j.bbrc.2005. 06.182]

Shrubsole, M.J., Lu, W., Chen, Z., et al., 2009. Drinking green tea modestly reduces breast cancer risk. J. Nutr., 139(2): 310-316. [doi:10.3945/jn.108.098699]

Shutava, T.G., Balkundi, S.S., Vangala, P., et al., 2009. Layerby-layer-coated gelatin nanoparticles as a vehicle for delivery of natural polyphenols. ACS Nano, 3(7):18771885. [doi:10.1021/nn900451a]

Siddiqui, I.A., Adhami, V.M., Bharali, D.J., et al., 2009. Introducing nanochemoprervention as a novel approach for cancer control: proof of principle with green tea polyphenol epigallocatechin-3-gallate. Cancer Res., 69(5): 1712-1716. [doi:10.1158/0008-5472.CAN-08-3978]

Siddiqui, I.A., Adhami, V.M., Ahmad, N., et al., 2010. 
Nanochemoprervention: sustained release of bioactive food components for cancer prevention. Nutr. Cancer, 62(7):883-890. [doi:10.1080/01635581.2010.509537]

Song, Y., Manson, J.E., Buring, J.E., et al., 2005. Associations of dietary flavonoids with risk of type 2 diabetes, and markers of insulin resistance and systemic inflammation in women: a prospective study and cross-sectional analysis. J. Am. Coll. Nutr., 24(5):376-384. [doi:10.1080/ 07315724.2005.10719488]

Suganuma, M., Okabe, S., Marino, M.W., et al., 1999. Essential role of tumor necrosis factor- $\alpha$ (TNF- $\alpha)$ in tumor promotion as revealed by TNF- $\alpha$-deficient mice. Cancer Res., 59(18):4516-4518.

Suganuma, M., Okabe, S., Kai, Y., et al., 2010. Synergistic effects of (-)-epigallocatechin-3-gallate with (-)-epicatechin, sulindac, or tamoxifen on cancer-preventive activity in the human lung cancer cell line PC-9. Cancer Res., 59(1): 44-47.

Suganuma, M., Saha, A., Fujiki, H., 2011. New cancer treatment stratedy using combination of green tea catechins and anticancer drugs. Cancer Sci., 102(2):317-323 [doi:10.1111/j.1349-7006.2010.01805.x]

Sun, C.L., Yuan, J.M., Lee, M.J., et al., 2002. Urinary tea polyphenols in relation to gastric and esophageal cancers: a prospective study of men in Shanghai, China. Carcinogenensis, 23(9):1497-1503. [doi:10.1093/carcin/23.9.1497]

Sun, C.L., Yuan, J.M., Koh, W.P., et al., 2006. Green tea and black tea and colorectal cancer risk: a meta-analysis of epidemiologic studies. Carcinogenesis, 27(7):1301-1309. [doi:10.1093/carcin/bg1024]

Sun, C.L., Yuan, J.M., Koh, W.P., et al., 2007. Green tea and black tea consumption in relation to colorectal cancer risk: the Singapore Chinese Health Study. Carcinogenesis, 28(10):2143-2148. [doi:10.1093/carcin/bgm171]

Suzuki, Y., Tsubono, Y., Nakaya, N., et al., 2004. Green tea and the risk of breast cancer: pooled analysis of two prospective studies in Japan. Br. J. Cancer, 90(7):13611363. [doi:10.1038/sj.bjc.6601652]

Tan, E.K., Tan, C., Fook-Chong, S.M., et al., 2003. Dosedependent protective effect of coffee, tea, and smoking in Parkinson's disease: a study in ethnic Chinese. J. Neurol. Sci., 216(1):163-167. [doi:10.1016/j.jns.2003.07.006]

Tang, N., Wu, Y., Zhou, B., et al., 2009. Green tea, black tea consumption and risk of lung cancer: a meta-analysis. Lung Cancer, 65(3):274-283. [doi:10.1016/j.lungcan. 2008.12.002]

Thielecke, F., Boschmann, M., 2009. The potential role of green tea catechins in the prevention of the metabolic syndrome - $\mathrm{a}$ review. Phytochemistry, 70(1):11-24. [doi:10.1016/j.phytochem.2008.11.011]

Tsuneki, H., Ishizuka, M., Terasawa, M., et al., 2004. Effect of green tea on blood glucose levels and serum proteomic patterns in diabetic $(\mathrm{db} / \mathrm{db})$ mice and on glucose metabolism in healthy humans. BMC pharmacol., 4(1):18. [doi:10.1186/1471-2210-4-18]

Ullmann, U., Haller, J., Decourt, J.P., et al., 2003. A single ascending dose study of epigallocatechin gallate in healthy volunteers. J. Int. Med. Res., 31(2):88-101. [doi:10.1177/147323000303100205]

Unno, T., Suzuki, Y., Kakuda, T., et al., 1999. Metabolism of theanine, $\gamma$-glutamylethylamide, in rats. J. Agric. Food
Chem., 47(4):1593-1596. [doi:10.1021/jf981113t]

Venables, M.C., Hulstron, C.J., Cox, H.R., et al., 2008. Green tea extract ingestion, fat oxidation, and glucose tolerance in healthy humans. Am. J. Clin. Nutr., 87(3):778-784.

Vernarelli, J.A., Lambert, J.D., 2013. Tea consumption is inversely associated with weight status and other markers for metabolic syndrome in US adults. Eur. J. Nutr., 52(3): 1039-1048. [doi:10.1007/s00394-012-0410-9]

Vita, J.A., 2003. Tea consumption and cardiovascular disease: effects on endothelial function. J. Nutr., 133(10):3293S3297S.

Wang, H., Wen, Y., Du, Y., et al., 2010. Effect of catechin enriched green tea on body composition. Obesity, 18(4): 773-779. [doi:10.1038/oby.2009.256]

Wu, A.H., Yu, M.C., 2006. Tea, hormone-related cancers and endogenous hormone levels. Mol. Nutr. Food Res., 50(2):160-169. [doi:10.1002/mnfr.200500142]

$\mathrm{Wu}$, A.H., Butler, L.M., 2011. Green tea and breast cancer. Mol. Nutr. Food Res., 55(6):921-930. [doi:10.1002/mnfr. 201100006]

Wu, A.H., Yu, M.C., Tseng, C.C., et al., 2003. Green tea and risk of breast cancer in Asian Americans. Int. J. Cancer, 106(4):574-579. [doi:10.1002/ijc.11259]

Wu, A.H., Yu, M.C., Tseng, C.C., et al., 2007. Body size, hormone therapy and risk of breast cancer in Asian American women. Int. J. Cancer, 120(4):844-852. [doi:10. 1002/ijc.22387]

Wu, C.H., Lu, F.H., Chang, T.C., et al., 2003. Relationship among habitual tea consumption, percent body fat, and body fat distribution. Obesity, 11(9):1088-1095. [doi:10. 1038/oby.2003.149]

Xu, R., Ye, H., Sun, Y., et al., 2012. Preparation, preliminary characterization, antioxidant, hepatoprotective and antitumor activities of polysaccharides from the flower of tea plant (Camellia sinensis). Food Chem. Toxicol., 50(7): 2473-2480. [doi:10.1016/j.fct.2011.10.047]

Yang, C.S., Hong, J., 2013. Prevention of chronic diseases by tea: possible mechanisms and human relevance. Ann. Rev. Nutr., 33(1):161-181. [doi:10.1146/annurev-nutr071811-150717]

Yang, C.S., Lee, M.J., Chen, L., et al., 1999. Human salivary tea catechin levels and catechin esterase activities implication in human cancer prevention studies. Cancer Epidemiol. Biomarkers Prev., 8(1):83-89.

Yang, C.S., Lu, F.H., Wu, J.S., et al., 2004. The protective effect of habitual tea consumption on hypertension. Arch. Intern. Med., 164(14):1534-1540. [doi:10.1001/archinte. 164.14.1534]

Yang, C.S., Lambert, J.D., Hou, Z., et al., 2006. Molecular targets for the cancer preventive activity of tea polyphenols. Mol. Carcinog., 45(6):431-435. [doi:10.1002/mc. 20228]

Yang, C.S., Wang, X., Lu, G., et al., 2009. Cancer prevention by tea: animal studies, molecular mechanisms and human relevance. Nat. Rev. Cancer, 9(6):429-439. [doi:10.1038/ nrc2641]

Yang, C.S., Wang, H., Li, G.X., et al., 2011. Cancer prevention by tea: evidence from laboratory studies. Pharmacol. Res. 64(2):113-122. [doi:10.1016/j.phrs.2011.03.001]

Yang, G., Shu, X.O., Li, H., et al., 2007. Prospective cohort study of green tea consumption and colorectal cancer risk 
in women. Cancer Epidemiol. Biomarkers Prev., 16(6): 1219-1223. [doi:10.1158/1055-9965.EPI-07-0097]

Yuan, J.M., Koh, W.P., Sun, C.L., et al., 2005. Green tea intake, $A C E$ gene polymorphism and breast cancer risk among Chinese women in Singapore. Carcinogenesis, 26(8):1389-1394. [doi:10.1093/carcin/bgi080]

Yuan, J.M., Sun, C., Butler, L.M., 2011. Tea and cancer prevention: epidemiological studies. Pharmacol. Res., 64(2): 123-135. [doi:10.1016/j.phrs.2011.03.002]

Yusuf, S., Hawken, S., Ôunpuu, S., et al., 2005. Obesity and the risk of myocardial infarction in 27000 participants from 52 countries: a case-control study. Lancet, 366(9497): 1640-1649. [doi:10.1016/S0140-6736(05)67663-5]

Zhang, M., Holman, C.D., Huang, J.P., et al., 2007. Green tea and the prevention of breast cancer: a case-control study in Southeast China. Carcinogenesis, 28(5):1074-1078. [doi:10.1093/carcin/bgl252]

Zhou, Y., Li, N., Zhuang, W., et al., 2008. Green tea and gastric cancer risk: meta-analysis of epidemiologic studies. Asia Pac. J. Clin. Nutr., 17(1):159-165.

Authors' Introduction:

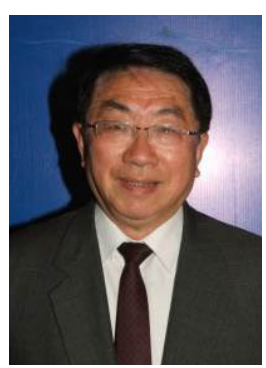

Prof. Zong-mao CHEN, was born in Shanghai in 1933. He entered the Fudan University from 1950, major in Entomology (1950-1952) and graduated from Shenyang Agricultural University in 1954, major in Plant Protection. He worked as a research scientist in Sugar Beet Institute, Chinese Academy of Agricultural Sciences (CAAS) from 1954 to 1960 and has worked in Tea Research Institute of CAAS since 1960. He visited Ciba-Geigy Company, Switzerland from May 1981 to December 1981 and visited as a visiting scholar in Pesticide Research Center, Michigan State University, USA, at May 1982 to May 1984. He conducted the research on the pesticide residues in tea since 1961, including the research in the contamination source of benzene hexachloride (BHC) and dichlorodiphenyltrichloroethane (DDT) in tea, the prediction of pesticide residue in tea according to the physic-chemical and ecological parameters. He was invited as the professor since 1974 and was appointed as the Director of the Tea Research Institute, CAAS in 1983-1994. He was elected as the Academician of Chinese Academy of Engineers in 2003 and was appointed as the President of the CCPR (FAO) in 2007-2010. His research achievements gained the National and Provincial Scientific and Technological Progress Prize for 3 times and 6 times, respectively. He also gained some honorable rewards from Ministry of Agriculture and Zhejiang Province Government. He published more than 200 papers in foreign and Chinese scientific journals and 6 monographs in the field of chemical ecology of insects, pesticide residue as well as tea and human health.

\section{中文概要}

题 目: 茶与人体健康: 茶叶活性组分的生物医学效应和 当前关注的若干问题

概 要：饮茶有益于健康的观念在我国已沿传多个世纪, 并在很大程度上为全世界所接受。本文简述了茶 叶的药用历史以及从中国传播到世界各地的历 史进程, 重点对国内外关于饮茶预防癌症、代谢 综合症、心血管疾病以及神经退行性疾病等人体 重要疾病的最新研究成果进行了综述。在此基础 上, 针对当前在动物实验和人体流行病学调查结 果上存在差异的原因, 特别是对茶叶中儿茶素类 化合物在人体组织中生物可利用度低的问题、高 剂量绿茶提取物对人体可能存在毒性等安全性 问题进行了讨论。此外, 还介绍了近几年在提高 儿茶素类化合物生物可利用度和对癌症的预防 和治疗效果上的最新进展。

关键词: 茶; 癌症; 代谢综合症; 心血管疾病; 神经退行 性疾病; 生物可利用度

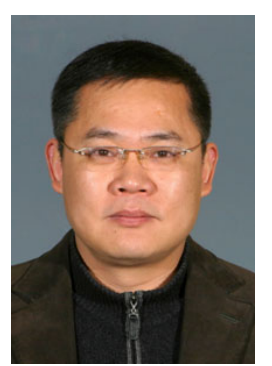

Prof. Zhi LIN, a tea scientist by training, received his BSc degree in Agronomy (1985) from the Southern Anhui Agricultural College of China, his MS degree in Agronomy (1988) from the Postgraduate School of Chinese Academy of Agricultural Sciences, and his PhD in Food Science (1999) from the Otsuma Women's University (Tokyo, Japan). He was the leader of the research group of Tea Processing Quality and Control, and Head of the Department of Science and Technology of Tea Research Institute, CAAS, and Head of the Tea Processing Lab of China Agriculture Research System. He is currently doing research on the key bioactive components in different kinds of tea and their changes during tea processing, technology of tea processing and new tea product developments. 